\title{
PROPAGACIÓN CLONAL in vitro DE Swietenia macrophylla King (CAOBA)
}

\author{
PROGRESS in vitro PROPAGATION Swietenia Macrophylla King (MAHOGANY)
}

\author{
Mercedes Carranza Patiño을 Héctor Reyes Morán², Washington Mora Silva ${ }^{1}$, Orly Cevallos Falquez ${ }^{1}$, Ariel Escobar Troya ${ }^{1}$, \\ María Cadme Arévalo ${ }^{1}$, José Nieto Rodríguez ${ }^{1}$, Jaime Morante Carriel ${ }^{1}$. \\ ${ }^{1}$ Dirección de Investigación Cientifica y Tecnológica, Laboratorio de Biotecnología, Universidad Técnica Estatal de Quevedo. \\ Campus Ing. Manuel Haz Álvarez, km 1.5 vía a Santo Domingo de los Tsáchilas. C. P. 73. Quevedo, Los Ríos, Ecuador. \\ ${ }^{2}$ Facultad de Ciencias Ambientales, Universidad Técnica Estatal de Quevedo. Campus Ing. Manuel Haz \\ Álvarez, km 1.5 vía a Santo Domingo de los Tsáchilas. C. P. 73. Quevedo, Los Ríos, Ecuador. \\ Emails: mcarranza@uteq.edu.ec; hec_forestal@yahoo.es; wmora@uteq.edu.ec; fcevallos@uteq.edu.ec; \\ telarieles@hotmail.com; mcadme@uteq.edu.ec; jnieto@uteq.edu.ec; jmorantec@gmail.com
}

\section{RESUMEN}

$\mathrm{L}$ a caoba (Swietenia macrophylla) es una especie forestal maderable de múltiples usos, apreciada por su dureza, resistencia, belleza y calidad. La explotación intensiva y un inadecuado sistema de aprovechamiento de la especie han ocasionado la disminución de la variabilidad genética, haciendo imposible la aplicación de programas de mejoramiento genético de caoba en el Ecuador. El cultivo in vitro es una técnica que ayudaría a disminuir este problema mediante la producción de plantas con alta robustez genética. El objetivo de esta investigación fue establecer un método que facilite la propagación in vitro de caoba a partir de segmentos nodales, empleados en la fase de establecimiento con diferentes concentraciones de $\mathrm{Ca}(\mathrm{ClO})_{2}$ y tiempos de exposición. La contaminación por microorganismos fue controlada con $15 \mathrm{~g}$ de $\mathrm{Ca}(\mathrm{ClO})_{2}$ durante $20 \mathrm{~min}$, alcanzando el $95 \%$ de sobrevivencia. Los explantes sanos fueron transferidos a un medio de cultivo MS/2 con distintos niveles de bencilaminopurina (BAP) y ácido indolbutírico (AIB) para su multiplicación in vitro, obteniéndose $70 \%$ de brotes con $2 \mathrm{mg} \mathrm{L}^{-1}$ de BAP en combinación con $1 \mathrm{mg} \mathrm{L}^{-1}$ de AIB. Los mejores brotes de la fase de multiplicación se colocaron en medio de cultivo $\mathrm{MS} / 2$ con diferentes concentraciones de ANA para facilitar su enraizamiento, ninguno de los tratamientos ensayados permitió generar raíces a los 21 días de su evaluación, aunque el mayor porcentaje de sobrevivencia (65\%) se obtuvo al combinar $2 \mathrm{mg} \mathrm{L}^{-1}$ BAP y $1 \mathrm{mg} \mathrm{L}^{-1}$ ANA.

Palabras clave: Protocolo, propagación in vitro, Swietenia macrophylla, segmentos nodales

Recibido: 02-abril-2013. Recibido en forma corregida: 5-Julio-2013.

Aceptado: 28-agosto-2013.

Publicado como ARTÍCULO CIENTÍFICO en Ciencia y Tecnología 6(2): 1-8

Julio-Diciembre de 2013

ISSN 1390-4051 impreso; ISSN 1390-4043 electrónico

(C) Ciencia y Tecnología. UTEQ. Quevedo-Ecuador
Abstract

$\mathrm{M}$ ahogany (Swietenia macrophylla), is a widely used timber tree species valued for its hardness, strength, beauty and quality. Intensive explotation and inadequate use of this species have resulted in the loss of genetic variability, making impossible the implementation of breeding programs of mahogany in Ecuador. In vitro culture is a promising technique that would help reducing this problem by producing plants with high genetic strength. The objective of this research was to establish a method to facilitate in vitro propagation of mahogany from nodal segments. In order to prevent contamination, nodal segments were treated with $\mathrm{Ca}(\mathrm{ClO})_{2}$ solution for $20 \mathrm{~min}$. Healthy explants were transferred to $\mathrm{MS} / 2$ culture medium with different concentrations of benzylaminopurine (BAP) and indolebutyric acid (IBA) for further in vitro proliferation, obtaining $70 \%$ of shoots on medium supplemented with $2 \mathrm{mg} \mathrm{L}^{-1}$ of BAP and $1 \mathrm{mg} \mathrm{L}^{-1}$ IBA. Bud treatment with different concentrations of ANA for in vitro rooting was not efficient, although the greatest survival rate $(65 \%)$ was obtained on culture medium containing $2 \mathrm{mg} \mathrm{L}^{-1} \mathrm{BAP}$ and $1 \mathrm{mg} \mathrm{L}^{-1} \mathrm{NAA}$.

Key words: Protocol, in vitro propagation, Swietenia macrophylla, nodal segments 


\section{INTRODUCCIÓN}

$\mathrm{L}$ a caoba (Swietenia macrophylla) se distribuye geográficamente en Belice, Brasil, Colombia, Costa Rica, El Salvador, Guatemala, Honduras, México, Nicaragua, Panamá, Perú, Venezuela y Ecuador en bosques nativos (Flora y Fauna Internacional, 2006). Está considerada una de las especies maderables más valiosas del mundo (Lamb, 1996). En plantaciones se obtiene subproductos como antipirético, tónico, astringente (RISE, 1995), producción de pulpa para papel, siendo Estados Unidos, Japón y el Reino Unido los principales importadores de caoba (Burley, 1987).

S. macrophylla, es una de las especies maderables con mayor índice de tala, más del $80 \%$ (Grogan et al., 2002). Sus poblaciones muestran indicios de declives y fragmentación en la mayor parte del área de distribución, provocando su disminución acelerada (Winograd, 1995), incluyéndola en la lista de especies en peligro de extinción por la Convención sobre el Comercio Internacional de Especies Amenazadas de Fauna y Flora Silvestre (CITES, 1994).

El factor biológico limitante para el desarrollo normal de árboles jóvenes de caoba está determinado en muchos casos por la susceptibilidad al ataque de Hypsipyla grandella Zell (Lepidoptera-Pyralidae), insecto barrenador de Meliáceas que ataca y consume los meristemos apicales y rebrotes (Howard y Mérida, 2004), reducción de fuste y muerte de la planta (Grogan et al., 2003 y Pérez et al., 2006).

Otros factores limitantes se deben a la baja germinación (10 al 70\%) lo cual reduce la propagación sexual de la caoba (Quinto et al., 2009), semillas de origen desconocido (Prado et al., 2012), ensayos insuficientes de selección basados en características fenotípicas y genotípicas, resultan plantaciones de alta heterogeneidad (Neill y Revelo, 1998).

La Organización de las Naciones Unidas para la Alimentación y Agricultura (FAO, 1994, 1997, 2001, 2010) sugiere mantener el recurso genético de la caoba de alta prioridad encontrándose por su situación en peligro de extinción (Jiménez et al., 1996). Una de las estrategias para superar las dificultades de propagación y evitar la extinción de especies valiosas, es el cultivo in vitro de tejido vegetal (Delgado et al., 2008). Esta técnica permite obtener plantas a partir de un fragmento pequeño de tejido cultivado en condiciones estériles (Murashige y Skoog, 1962). La propagación in vitro vía organogénesis directa incrementa de forma rápida el número de individuos, etapa importante en la producción de plántulas a nivel industrial y un banco de germoplasma con fines de rescate (Uribe et al., 2008). Además, permite obtener plantas libres de enfermedades, en algunas ocasiones reduce el tiempo de propagación
(Rebolledo et al., 2006). Debido a las dificultades de propagación sexual de caoba y escasa información disponible de propagación in vitro (Valverde et al., 1998 y Collado et al., 2004), se ha propuesto establecer un método reproducible que facilite el establecimiento y multiplicación de plantas de caoba, mediante la aplicación de técnicas de cultivo in vitro, vía organogénesis directa con fines de recuperación.

\section{Materiales y MÉTODOS}

E ste trabajo se realizó en el laboratorio de cultivo de tejidos vegetales de la Universidad Técnica Estatal de Quevedo, Ecuador, durante el año 2012.

\section{Material vegetal y preparación de los explantes}

Se empleó segmentos nodales de plantas de caoba de seis meses de edad de la Estación Experimental Boliche del Instituto Nacional Autónomo de Investigaciones Agropecuarias (INIAP)-Ecuador. Previo a la recolección de los explantes, las plantas fueron trasladadas hasta el invernadero del Laboratorio de Biotecnología. Fumigadas dos veces por semana con mezcla de Agrimicin y Benlate a una concentración de $1 \mathrm{~g} \mathrm{~L}^{-1}$ (Araya, 2006) para disminuir la contaminación de los segmentos nodales en el establecimiento in vitro (Figura 1A) (Rebolledo et al., 2006 y Flores et al., 2009).

\section{Medios de cultivo}

Se empleó el medio de cultivo MS propuesto por Murashige y Skoog (1962) y Uribe et al. (2008), suplementado con bacto agar (Becton, Dickinson and Company) $\left(7 \mathrm{~g} \mathrm{~L}^{-1}\right)$ como agente gelificante y los nitratos al 50\% (MS/s) (Collado et al., 2004 y Pierik, 1990), sacarosa (20 $\left.\mathrm{g} \mathrm{L}^{-1}\right), 20 \mathrm{mg} \mathrm{L}^{-1}$ de gentamicina. El $\mathrm{pH}$ ajustado a 5.7 con $\mathrm{NaOH}$ a una concentración $0.1 \mathrm{~N}$. El medio fue químicamente esterilizado con vitrofural al $0.116 \mathrm{~g} \mathrm{~L}^{-1}$, en la cámara de flujo laminar.

\section{Fases de la propagación in vitro}

Establecimiento aséptico del cultivo. Explantes de 2.5 y $3.5 \mathrm{~cm}$ de longitud fueron sumergidos en 100 $\mathrm{mL}$ de agua destilada estéril con 2 gotas de tween 20 (polioxietileno de sorbitan, un detergente líquido) durante dos minutos, transferidos a 10 y $15 \mathrm{~g}$ de hipoclorito de calcio en $100 \mathrm{~mL}$ de agua destilada durante 10, 15 y 20 minutos, con tres enjuagues de agua destilada estéril. El último enjuague los explantes fueron sumergidos en gentamicina de $20 \mathrm{mg} \mathrm{L}^{-1}$ por 20 minutos en cámara de flujo laminar vertical (figura 1AB). Los explantes fueron sembrados en tubos de ensayo 
con $15 \mathrm{~mL}$ de medio de cultivo e incubados a $25^{\circ} \mathrm{C} \pm 1^{\circ}$ $\mathrm{C}$ durante 21 días.

Fase de multiplicación. Subsiguientemente, explantes libres de agentes contaminantes de entre 1.5 y $2 \mathrm{~cm}$ de longitud, fueron transferidos a un medio de cultivo MS de multiplicación, con bencilaminopurina (BAP) $(1,2$ y $\left.3 \mathrm{mg} \mathrm{L}^{-1}\right)$ y ácido indolbutírico (AIB) $\left(0.5\right.$ y $\left.1 \mathrm{mg} \mathrm{L}^{-1}\right)$, siguiendo el método descrito por Gupta et al. (1980). Se efectuaron tres siembras a intervalos constantes de 21 días.

Fase de enraizamiento. Se seleccionaron brotes de 3 $\mathrm{cm}$ de longitud de la fase de multiplicación, se ubicaron en el medio de cultivo MS con AIB a concentraciones de 1; 1.5; 2 y $2.5 \mathrm{mg} \mathrm{L}^{-1}$ (Figura 1E). Los explantes fueron evaluados a los 21 días de su establecimiento. En el Cuadro 1 se muestran los tratamientos y las variables evaluadas en las distintas fases de la propagación in vitro.

Incubación y fotoperíodo de vitroplantas. La incubación en las tres etapas se efectuó en una cámara de cultivo con intensidad lumínica de $50 \mu \mathrm{mol} \mathrm{m} \mathrm{m}^{-2} \mathrm{~s}^{-1}$ con un fotoperíodo de $16 \mathrm{~h}$ y temperatura de $25 \pm 1^{\circ} \mathrm{C}$.

\section{Diseño experimental y análisis estadístico}

Para analizar las condiciones del ensayo en la fase de establecimiento, se empleó un Diseño Completo al Azar (DCA) con arreglo factorial (2x3) (Cuadro 1) con seis tratamientos, cuatro repeticiones. En la fase de multiplicación, se aplicó un DCA con arreglo factorial $(3 \times 2)$ (Cuadro 1), con seis tratamientos, cuatro repeticiones. La fase de enraizamiento, se evaluó mediante un DCA con cuatro tratamientos, cuatro repeticiones. Se utilizaron cinco unidades experimentales en cada fase.

Los datos de cada una de las variables se sometieron a un análisis de varianza ANDEVA y separación de medias al 95\% de probabilidad, empleando el programa estadístico MSTAT-C (Michigan State University, 1983). Para establecer diferencias estadísticas entre tratamientos se efectuó la Prueba de Rangos Múltiples de Tukey $(\mathrm{p}<0.05)$. Los datos con valores cero fueron transformados con la siguiente fórmula: $\sqrt{ }(x+0.5)$.

Cuadro 1. Tratamientos y variables evaluadas en las distintas fases de la propagación in vitro de Swietenia macrophylla King (caoba)

\begin{tabular}{|c|c|}
\hline Fases de la propagación in vitro & Variables analizadas por fase \\
\hline \multicolumn{2}{|l|}{ Establecimiento } \\
\hline $\mathrm{T} 110 \mathrm{~g} \mathrm{Ca}(\mathrm{ClO})_{2}$ por $10 \mathrm{~min}$ & Contaminación hongos \\
\hline $\mathrm{T} 210 \mathrm{~g} \mathrm{Ca}(\mathrm{ClO})_{2}$ por $15 \mathrm{~min}$ & Contaminación bacterias \\
\hline $\mathrm{T} 310 \mathrm{~g} \mathrm{Ca}(\mathrm{ClO})_{2}$ por $20 \mathrm{~min}$ & Número de explantes quemados (necrosis) \\
\hline $\mathrm{T} 415 \mathrm{~g} \mathrm{Ca}(\mathrm{ClO})_{2}$ por $10 \mathrm{~min}$ & Porcentaje de explantes vivos \\
\hline T5 $15 \mathrm{~g} \mathrm{Ca}(\mathrm{ClO})_{2}$ por $15 \mathrm{~min}$ & Número de brotes \\
\hline $\mathrm{T} 615 \mathrm{~g} \mathrm{Ca}(\mathrm{ClO})_{2}$ por $20 \mathrm{~min}$ & Longitud de brotes \\
\hline \multicolumn{2}{|l|}{ Multiplicación } \\
\hline T1 $1 \mathrm{mg} \mathrm{L}^{-1} \mathrm{BAP}+0.5 \mathrm{mg} \mathrm{L}^{-1} \mathrm{AIB}$ & Contaminación hongos \\
\hline T2 $1 \mathrm{mg} \mathrm{L}-1 \mathrm{BAP}+1 \mathrm{mg} \mathrm{L}^{-1} \mathrm{AIB}$ & Contaminación bacterias \\
\hline T3 $2 \mathrm{mg} \mathrm{L}^{-1} \mathrm{BAP}+0.5 \mathrm{mg} \mathrm{L}^{-1} \mathrm{AIB}$ & Porcentaje de brotes \\
\hline T4 $2 \mathrm{mg} \mathrm{L}^{-1} \mathrm{BAP}+1 \mathrm{mg} \mathrm{L}^{-1} \mathrm{AIB}$ & Número de brotes \\
\hline $\mathrm{T} 53 \mathrm{mg} \mathrm{L}^{-1} \mathrm{BAP}+0.5 \mathrm{mg} \mathrm{L}^{-1} \mathrm{AIB}$ & Longitud de brote mayor \\
\hline \multicolumn{2}{|l|}{ T6 $3 \mathrm{mg} \mathrm{L}^{-1} \mathrm{BAP}+1 \mathrm{mg} \mathrm{L}^{-1} \mathrm{AIB}$} \\
\hline \multicolumn{2}{|l|}{ Enraizamiento } \\
\hline T1 $1 \mathrm{mg} \mathrm{L}-1 \mathrm{BAP}+0.5 \mathrm{mg} \mathrm{L}^{-1} \mathrm{ANA}$ & Contaminación hongos \\
\hline T2 $1 \mathrm{mg} \mathrm{L}-1 \mathrm{BAP}+1 \mathrm{mg} \mathrm{L}^{-1}$ ANA & Contaminación bacterias \\
\hline $\mathrm{T} 32 \mathrm{mg} \mathrm{L}^{-1} \mathrm{BAP}+0.5 \mathrm{mg} \mathrm{L}^{-1} \mathrm{ANA}$ & Porcentaje de explantes vivos \\
\hline \multirow[t]{2}{*}{ T4 $2 \mathrm{mg} \mathrm{L}{ }^{-1} \mathrm{BAP}+1 \mathrm{mg} \mathrm{L}^{-1} \mathrm{ANA}$} & Número de raíces \\
\hline & Longitud de raíces \\
\hline
\end{tabular}




\section{RESUltados Y Discusión}

\section{Fase de establecimiento}

La contaminación por bacterias, número de brotes y longitud de brotes (tratamientos T3, T6 y T5) no mostraron diferencia $(\mathrm{p}<0.05)$. En los explantes contaminados por hongos, quemados y vivos (\%), se observan diferencias notables $(\mathrm{p}<0.05)$, obteniendo los promedios más altos en los tratamientos T2, T5 y T6. Al aplicar $15 \mathrm{~g}$ de hipoclorito de calcio durante 20 minutos (T6), no se observó diferencias, alcanzando un 95\% de explantes vivos, libres de contaminación por hongos y bacterias a los 21 días de evaluación (Cuadro 2).

Los resultados obtenidos en esta fase, superan a los descritos para Tectona grandis utilizando hipoclorito de calcio al $4 \%$ por 10 minutos con $31.67 \%$ de explantes vivos (Abdelnour y Muñoz, 2005). Mroginski et al. (2003) al emplear $1.8 \%$ de $\mathrm{NaOCl}$ por 30 min encontraron un $35 \%$ de contaminación en el establecimiento in vitro de yemas axilares de Toona ciliata (Meliaceae) de 2 años de edad. Flores et al. (2009) en Ficus carica, al emplear hipoclorito de calcio al 8 y $10 \%$ por 10 y 20 min, obtiene un $64 \%$ de sobrevivencia, respectivamente. Pérez et al. (2012) aplicaron hipoclorito de sodio al 10\% durante $10 \mathrm{~min}$ en explantes de caoba, logrando reducir la contaminación hasta un 14\%.

Aunque los problemas en el establecimiento in vitro de especies leñosas, se debe en gran medida a la contaminación microbiana de los explantes provenientes del invernadero, los resultados obtenidos sugieren que la contaminación presente en el material vegetal de caoba puede ser impedido mediante la desinfección con $\mathrm{Ca}(\mathrm{ClO})_{2}$ o por la adición de éste al medio de cultivo.

\section{Fase de multiplicación}

Si bien, no se encontró diferencias $(\mathrm{p}<0.05)$ entre los tratamientos (Cuadro 3), al añadir $2 \mathrm{mg} \mathrm{L}^{-1}$ de BAP en combinación con $1 \mathrm{mg} \mathrm{L}^{-1}$ de AIB, se obtuvo el $70 \%$ de explantes con brotes y un promedio de $0.17 \mathrm{~cm}$ de longitud (T4). Estos resultados son superiores a los obtenidos por Collado et al. (2004) quienes alcanzaron un $63.9 \%$ de explantes brotados con $0.2 \mathrm{mg} \mathrm{L}^{-1}$ de 6-BAP empleando ápices y segmentos nodales de caoba. Según Vázquez y Torres (1995) el comportamiento de los explantes en esta fase de la propagación in vitro requiere un adecuado balance endógeno de reguladores del crecimiento, siendo imprescindible para la multiplicación in vitro de tejidos vegetales.

La combinación de BAP y AIB incrementaron el porcentaje de explantes brotados al efecto sobre la división celular. Además, Tacoronte (1998) desarrolló yemas axilares en segmentos nodales de plantas de caoba germinadas in vitro en el medio de cultivo MS/2 con la utilización de BA (benciladenina), $2 \mathrm{mg} \mathrm{L}^{-1}$ y AIA (ácido indol acético), $2 \mathrm{mg} \mathrm{L}^{-1}$, con un porcentaje de brotes inferior a los obtenidos en este trabajo.

El efecto inhibitorio en la emisión y elongación de los brotes por aumento en la concentración exógena de hormonas es diferente dependiendo del tipo de hormona a emplear, reducción de los niveles, ya sea de auxina o citoquinina, teniendo efectos distintos sobre el desarrollo de las plántulas in vitro (Sánchez et al., 2004). Para inducir la división y elongación celular, es necesario un balance apropiado entre citoquininas y auxinas, en un medio nutritivo, además de las que se encuentran

Cuadro 2. Establecimiento aséptico de segmentos nodales para el cultivo in vitro de Swietenia macrophylla King (caoba)

\begin{tabular}{|c|c|c|c|c|c|c|}
\hline & T1 & $\mathbf{T 2}$ & T3 & T4 & T5 & T6 \\
\hline Variables & $\begin{array}{c}10 \mathrm{~g} \\
\mathrm{Ca}(\mathrm{ClO})_{2} \\
10 \mathrm{~min}\end{array}$ & $\begin{array}{c}10 \mathrm{~g} \\
\mathrm{Ca}(\mathrm{ClO})_{2} \\
15 \mathrm{~min}\end{array}$ & $\begin{array}{c}10 \mathrm{~g} \\
\mathrm{Ca}(\mathrm{ClO})_{2} \\
20 \mathrm{~min}\end{array}$ & $\begin{array}{c}15 \mathrm{~g} \\
\mathrm{Ca}(\mathrm{ClO})_{2} \\
10 \mathrm{~min}\end{array}$ & $\begin{array}{c}15 \mathrm{~g} \\
\mathrm{Ca}(\mathrm{ClO})_{2} \\
15 \mathrm{~min}\end{array}$ & $\begin{array}{c}15 \mathrm{~g} \\
\mathrm{Ca}(\mathrm{ClO})_{2}\end{array}$ \\
\hline Número de bacterias & $0.30 \mathrm{a}$ & $0.25 \mathrm{a}$ & $0.40 \mathrm{a}$ & $0.35 \mathrm{a}$ & $0.19 \mathrm{a}$ & $0.00 \mathrm{a}$ \\
\hline Número de hongos & $0.30 \mathrm{~b}$ & $0.70 \mathrm{a}$ & $0.25 \mathrm{~b}$ & $0.15 \mathrm{bc}$ & $0.10 \mathrm{bc}$ & $0.00 \mathrm{c}$ \\
\hline Número de explantes quemados & $0.05 \mathrm{~b}$ & $0.00 \mathrm{~b}$ & $0.10 \mathrm{ab}$ & $0.05 \mathrm{ab}$ & $0.20 \mathrm{a}$ & $0.00 \mathrm{~b}$ \\
\hline Explantes vivos (\%) & $35.00 \mathrm{bc}$ & $5.00 \mathrm{c}$ & $25.00 \mathrm{bc}$ & $35.00 \mathrm{bc}$ & $55.00 \mathrm{ab}$ & $95.00 \mathrm{a}$ \\
\hline Número de brotes & $0.60 \mathrm{a}$ & $0.05 \mathrm{~b}$ & $0.25 \mathrm{ab}$ & $0.40 \mathrm{ab}$ & $0.55 \mathrm{a}$ & $0.65 \mathrm{a}$ \\
\hline Longitud de brotes $(\mathrm{cm})$ & $0.53 \mathrm{a}$ & $0.13 \mathrm{a}$ & $0.20 \mathrm{a}$ & $0.63 \mathrm{a}$ & $0.75 \mathrm{a}$ & $0.63 \mathrm{a}$ \\
\hline DE* & 0.34 & 0.25 & 0.31 & 0.31 & 0.33 & 0.19 \\
\hline
\end{tabular}

*DE=Desviación Estándar. Medias seguidas por la misma letra no presentan diferencias estadísticas (Tukey, p>0.05). 
Cuadro 3. Fase de multiplicación in vitro de segmentos nodales de Swietenia macrophylla King (caoba)

\begin{tabular}{|c|c|c|c|c|c|c|}
\hline & T1 & $\mathbf{T 2}$ & T3 & T4 & T5 & T6 \\
\hline Variables & $\begin{array}{l}1 \mathrm{mg} \mathrm{L}^{-1} \mathrm{BAP}+ \\
0.5 \mathrm{mg} \mathrm{L}^{-1} \mathrm{AIB}\end{array}$ & $\underset{1 \mathrm{mg} \mathrm{L}^{-1} \mathrm{AIB}}{1 \mathrm{mg} \mathrm{L}^{-1} \mathrm{BAP}+}$ & $\begin{array}{l}2 \mathrm{mg} \mathrm{L}^{-1} \text { BAP+ } \\
0.5 \mathrm{mg} \mathrm{L}^{-1} \mathrm{AIB}\end{array}$ & $\begin{array}{c}2 \mathrm{mg} \mathrm{L}^{-1} \mathrm{BAP}+ \\
1 \mathrm{mg} \mathrm{L}^{-1} \mathrm{AIB}\end{array}$ & $\begin{array}{l}3 \mathrm{mg} \mathrm{L}^{-1} \mathrm{BAP}+ \\
0.5 \mathrm{mg} \mathrm{L}^{-1} \mathrm{AIB}\end{array}$ & $\begin{array}{c}3 \mathrm{mg} \mathrm{L}^{-1} \text { BAP+ } \\
1 \mathrm{mg} \mathrm{L}^{-1} \mathrm{AIB}\end{array}$ \\
\hline Número de bacterias & $0.35 \mathrm{a}$ & $0.10 \mathrm{a}$ & $0.15 \mathrm{a}$ & $0.05 \mathrm{a}$ & $0.35 \mathrm{a}$ & $0.15 \mathrm{a}$ \\
\hline Número de hongos & $0.30 \mathrm{a}$ & $0.50 \mathrm{a}$ & $0.15 \mathrm{a}$ & $0.15 \mathrm{a}$ & $0.45 \mathrm{a}$ & $0.50 \mathrm{a}$ \\
\hline Explantes vivos (\%) & $35.00 \mathrm{a}$ & $35.00 \mathrm{a}$ & $65.00 \mathrm{a}$ & $70.00 \mathrm{a}$ & $30.00 \mathrm{a}$ & $50.00 \mathrm{a}$ \\
\hline Número de brotes & $0.35 \mathrm{a}$ & $0.40 \mathrm{a}$ & $0.65 \mathrm{a}$ & $0.70 \mathrm{a}$ & $0.40 \mathrm{a}$ & $0.45 \mathrm{a}$ \\
\hline Longitud de brotes $(\mathrm{cm})$ & $0.09 \mathrm{a}$ & $0.08 \mathrm{a}$ & $0.17 \mathrm{a}$ & $0.07 \mathrm{a}$ & $0.03 \mathrm{a}$ & $0.16 \mathrm{a}$ \\
\hline $\mathrm{DE}^{*}$ & 0.11 & 0.03 & 0.05 & 0.08 & 0.10 & 0.03 \\
\hline
\end{tabular}

*DE=Desviación Estándar. Medias seguidas por la misma letra no presentan diferencias estadísticas (Tukey, p >0.05).

en forma endógena en los explantes in vitro ( $\mathrm{Cob}$ et al., 2010; Martínez y Pacheco, 2006). Los resultados encontrados en esta investigación respecto del número de brotes (0.35 a 0.70) concuerdan con lo expresado por Bernal et al. (2009), que los requerimientos de citoquinina en las plantas in vitro son extremadamente variables y las respuestas a la inducción de brotes dependen del contenido endógeno de cada especie y del tipo de explante utilizado.

La aplicación de los reguladores del crecimiento al medio de cultivo va a depender del tipo de diferenciación que se desea obtener. La estimulación de las yemas terminales en la etapa de micropropagación se suele realizar mediante el empleo de bencilaminopurina (BAP), puesto que esta citoquinina aplicada en bajas concentraciones, promueve no sólo la división celular sino también la brotación y elongación de las yemas (Collado et al., 2004). En éste estudio, la combinación de BAP y AIB, en una relación 2:1 $\mathrm{mg} \mathrm{L}^{-1}$ fue suficiente para conseguir alto porcentaje de brotación y aceptable longitud de brotes de caoba.

\section{Fase de enraizamiento}

De todos los tratamientos aplicados en la fase de enraizamiento (cuadro 4) ninguno permitió la formación de raíces, sin embargo, con el tratamiento T4: $2 \mathrm{mg} \mathrm{L}^{-1} \mathrm{BAP}+1 \mathrm{mg} \mathrm{L}^{-1}$ ANA se obtuvo un $65 \%$ de explantes vivos. Estos resultados fueron similares a los descritos por Bernal et al. (2009) en el enraizamiento y aclimatización de vitroplantas de S. macrophylla. La baja capacidad de enraizamiento se mostró con la auxina AIB, inhibida completamente en las diferentes concentraciones utilizadas. En Tectona grandis (Teca) la respuesta rizogenética fue de $13.3 \%$ al utilizar 3 mg L ${ }^{-1}$ de ANA y $18 \%$ al emplear $2.5 \mathrm{mg} \mathrm{L}^{-1}$ de AIB enraizaron (Abdelnour y Muñoz, 2005).

Silva et al. (2010) indican que no todas las auxinas naturales o sintéticas pueden inducir primordios radicales in vitro. En algunas especies vegetales se dificulta el arraigado aún en presencia de auxinas, siendo otros factores los que influyen en la inducción de raíces (Vázquez y Torres, 1995). Algunas especies de plantas no necesitan pasar por la etapa de enraizamiento y emiten sus raíces en el mismo medio de cultivo donde

Cuadro 4. Fase de enraizamiento in vitro de yemas axilares de Swietenia macrophylla King (caoba)

$\begin{array}{llll}\text { T1 } & \text { T2 } & \text { T3 } & \text { T4 }\end{array}$

\begin{tabular}{|c|c|c|c|c|}
\hline Variables & $\begin{array}{l}1 \mathrm{mg} \mathrm{L}^{-1} \text { BAP + } \\
0.5 \mathrm{mg} \mathrm{L}^{-1} \text { AIB }\end{array}$ & $1 \mathrm{mg} \mathrm{L}^{-1}$ BAP + & $\begin{array}{l}2 \mathrm{mg} \mathrm{L} \mathrm{L}^{-1} \text { BAP }+ \\
0.5 \mathrm{mg} \mathrm{L}^{-1} \text { ANA }\end{array}$ & $\underset{1 \mathrm{mg} \mathrm{L}^{-1} \text { ANA }}{2 \mathrm{mg} \mathrm{L}^{-1} \text { + }}$ \\
\hline Número de bacterias & $0.50 \mathrm{a}$ & $0.20 \mathrm{~b}$ & $0.20 \mathrm{~b}$ & $0.20 \mathrm{~b}$ \\
\hline Número de hongos & $0.05 \mathrm{a}$ & $0.05 \mathrm{a}$ & $0.10 \mathrm{a}$ & $0.00 \mathrm{a}$ \\
\hline Explantes vivos (\%) & $25.00 \mathrm{~b}$ & $50.00 \mathrm{ab}$ & $20.00 \mathrm{~b}$ & $65.00 \mathrm{a}$ \\
\hline Número de raíces & $0.25 \mathrm{a}$ & $0.95 \mathrm{a}$ & $0.25 \mathrm{a}$ & $0.70 \mathrm{a}$ \\
\hline Longitud de raíces $(\mathrm{cm})$ & $0.15 \mathrm{a}$ & $0.55 \mathrm{a}$ & $0.10 \mathrm{a}$ & $0.25 \mathrm{a}$ \\
\hline $\mathrm{DE}^{*}$ & 0.11 & 0.16 & 0.09 & 0.08 \\
\hline
\end{tabular}

*DE=Desviación Estándar. Medias seguidas por la misma letra no presentan diferencias estadísticas (Tukey, p>0.05). 
desarrollan yemas nuevas, ocurriendo el proceso de multiplicación y enraizamiento en forma simultánea (Sánchez et al., 2004). En esta investigación se realizó una combinación de citoquinina BAP y la auxina AIA, siendo la más utilizada en la inducción radical (Collado et al., 2004).

\section{Identificación de agentes patógenos}

En el proceso de la propagación in vitro de caoba se evidenció la presencia de diversos hongos filamentosos, así como bacterias en los diferentes tratamientos. La clasificación y detección se realizó a nivel de género en el caso de hongos, de acuerdo a claves taxonómicas (Barnett y Hunter, 1972). Uno de los hongos encontrados en el cultivo in vitro de caoba pertenece al género Curvularia. Estos resultados coinciden con los descritos por Acosta et al. (2002) quien encontró varios géneros de hongos contaminantes en el establecimiento in vitro de árboles leñosos, incluido Curvularia.

A pesar de que se han implementado protocolos para propagar un gran número de especies forestales por cultivo in vitro, la contaminación fúngica y bacteriana de los explantes constituye uno de los problemas que limita su aplicación (Acosta et al., 2009 y Alvarado, 1998). Los principales microorganismos contaminantes del cultivo in vitro son los hongos filamentosos, las levaduras y las bacterias, los cuales habitan comúnmente plantas in vivo, pero tienen efectos devastadores en el cultivo in vitro (George, 1993; Leifert et al., 1994; Leifert y Cassells, 2001).

En la Figura 1, se muestran los resultados de la propagación in vitro de caoba, desde la desinfección de los segmentos nodales hasta su multiplicación y enraizamiento.

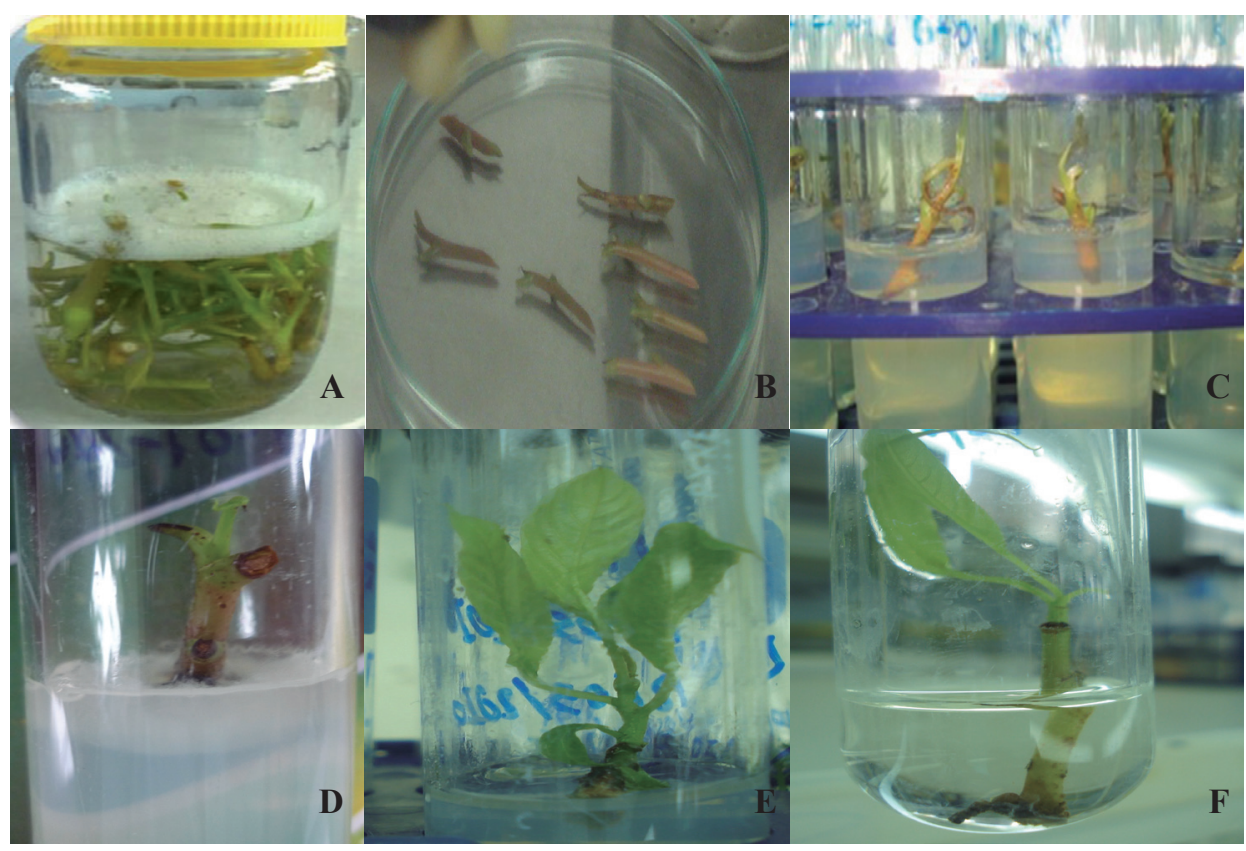

Figura 1. Desinfección de explantes (A), explantes en la fase de establecimiento aséptico (B, C), explante contaminado por hongo (D), fase de multiplicación $(E)$, fase de enraizamiento (F)

\section{Conclusiones}

E $\mathrm{n}$ la fase de establecimiento in vitro de explantes de caoba, se demuestra que la aplicación de $15 \mathrm{~g}$ de hipoclorito de calcio durante $20 \mathrm{~min}$, permite reducir significativamente la contaminación de los explantes por microorganismos. En la fase de multiplicación in vitro, el medio MS suplementado con $2 \mathrm{mg} \mathrm{L}^{-1}$ de BAP y $1 \mathrm{mg} \mathrm{L}^{-1}$ de AIB, permitió generar el $70 \%$ de brotes sanos.

El enraizamiento de brotes de caoba en dosis combinadas de BAP/AIB y BAP/ANA, no presentó efecto alguno. La ausencia de raíces puede estar asociada al corto periodo de evaluación de los explantes y a las bajas dosis. Siendo necesario, evaluar concentraciones de BAP, ANA y AIA superiores a $2 \mathrm{mg}$ $\mathrm{L}^{-1}$. El establecimiento de segmentos nodales de caoba tiene gran importancia ya que por vez primera se ha logrado obtener una metodología reproducible para la propagación in vitro de esta especie en el Ecuador. 


\section{LiTERATURA CITADA}

Abdelnour, A., A. Muñoz. 2005. Micropropagación de teca (Tectona grandis L.f). Kurú: Revista Forestal 2(5): 11

Araya, J. 2006. Establecimiento in vitro de cuatro variedades de caña de azúcar a partir de explantes foliares y yemas axilares. Proyecto presentado como requisito para optar al título de Ingeniero Agrónomo. Zamorano, p. 26-30.

Acosta, M., Y. Alvarado, I. Caballero. 2002. Micobiota epifítica y contaminantes fungosos del establecimiento in vitro de la guayaba (Psidium guajava L.). Biotecnología Vegetal 2(2): 67-71.

Acosta, M., Y. Alvarado, M. Cruz, M. Leiva, C. Sánchez, B. Roque, E. Quiala, M. Chávez, F. Jiménez, R. Barbón, R. Collado, M. Rodríguez, M. Feria, I. Borroto, M. Pérez. 2009. Microbiota de plantas donadoras y hongos filamentosos contaminantes del establecimiento in vitro de cinco especies forestales. Cuba. Biotecnología Vegetal 9(2): 99103.

Alvarado, Y. 1998. Contaminación microbiana en el cultivo in vitro de plantas. In Pérez, J. (Ed) Propagación y Mejora Genética de Plantas por Biotecnología. Santa Clara, CU, Instituto de Biotecnología de las Plantas. p. 81-104.

Barnett, H., B. Hunter. 1972. Illustrated Genera of Imperfect Fungi. 3 ed. Estados Unidos: Burgess Publishing Company.

Bernal, J., A. Rojas, A. Hine. 2009. Optimización del proceso de enraizamiento y aclimatización de vitroplantas de Swietenia macrophylla King (Orden: Meliácea), Tecnología en Marcha 22(3): 34-41.

Burley, J. 1987. Applications of biotechnology in silviculture and development rural. Common. Mérida, Venezuela. Forest Review 66(4): 357-367.

CITES. 1994. Proposal to include in Appendix II Neotropical populations of Swietenia macrophylla and natural hybrids with $S$. Mahagoni and $S$. Humilis. Ninth Meeting of the conference of the parties. Fort Lauderdale, Florida, USA.

Cob, J., A. Sabja, D. Ríos, A. Lara, P. Donoso, L. Arias, B. Escobar. 2010. Potencial de la organogénesis como estrategia para la masificación in vitro de Persea lingue en la zona Centro-Sur de Chile. Bosque (Valdivia) 31(3): 202-208

Collado, R., R. Barbón, D. Agramonte, F. Jiménez, M. Pérez, G. Odalys, D. Ramírez. 2004. Establecimiento in vitro de ápices y segmento nodales de Swietenia macrophylla King, Universidad Central "Marta Abreu”, Cuba. Biotecnología Vegetal 4(3): 143146.
Delgado, M. F., M. Cuba, P. Hechenleitner, O. Thiers. 2008. Propagación vegetativa de taique (Desfontainia spinosá) y tepa (Laureliopsis philippiana) con fines ornamentales. Bosque (Valdivia) 29(2): 120-126.

FAO. 1994. Informe: Cuadro de Expertos de la FAO en recursos genéticos forestales. Octava Reunión. FO: FGR/8/Rep. Roma, Italia, 28-30 de junio de $1993.57 \mathrm{p}$.

FAO. 1997. Informe: Cuadro de Expertos de la FAO en recursos genéticos forestales. Novena Reunión. FO: FRG/9/ Rep. Roma, p. 58.

FAO. 2001. Situación de los Bosques del Mundo 2001. Organización de las Naciones Unidas para la Agricultura y la Alimentación, Roma, Italia.

FAO. 2010. FAO Forestry, XIII World Forestry Congress. Unasylva. 61(234-235): 71-73.

Flora y Fauna Internacional. 2006. Estado y aprovechamiento sostenible de la caoba en Centroamérica. Reino Unido, ISBN 1903703212. $48 \mathrm{p}$.

Flores, M., V. Jiménez, R. Chacon. 2009. Cultivo de tejidos en Ficus carica con miniestacas, Revista Forestal Agronomía Mesoamericana 20(2): 319325.

George, E. F. 1993. Plant propagation by tissue culture. 2 ed. p. 130-143.

Grogan J., M. Ashton, J. Galvao. 2003. Big-leaf mahogany (Swietenia macrophylla) seedling survival and growth across a topographic gradient in southeast Pará, Brasil. Forest Ecology and Management 186: 311-326.

Grogan, J., P. Barreto, A. Veríssimo. 2002. Mahogany in the brazilian amazon: Ecology and perspectives on management / Mogno na Amazônia Brasileira: Ecologia e perspectivas de manejo. Belén (Brasil), Instituto do Homem e Meio Ambiente da Amazonia. $58 \mathrm{p}$

Gupta, P., A. Nadgir, A. Mascarenhas, V. Fagannathan. 1980. Tissue culture of foresta trees: clonal multiplication of Tectona grandis L. (teak) by tissue culture. Plant Science Letters 17:259-268.

Howard, F. W., M. A. Mérida. 2004. El taladrador de las meliáceas, Hypsipyla grandella (Zeller) (Insecta: Lepidoptera: Pyralidae: Phycitinae). EDIS/IFAS, University of Florida. Document EENY-337. (en línea). Disponible http://edis.ifas.ufl.edu/ document in614.

Jiménez, H., E. Alpizar, J. Ledezma, J. Tosi, R. Bolanos, R. Solórzano, J. Echeverría, P. Onorio, M. Castillo, R. Macilla. 1996. Estudio sobre el estado de regeneración natural de Swietenia macrophylla 
King "Mara" en Santa Cruz, Bolivia. World Wildlife Fund. p. 102.

Lamb, F. B. 1996. Mahogany of tropical America: Its ecology and management, Ann. Arbor: University of Michigan Press, p. 219.

Leifert, C., C. Morris, W. Waites. 1994. Ecology of microbial saprophytes and pathogens in tissue cultura and field grown plants: reason for contamination problems in vitro. Critical Reviews in Plant Sciences 13:139-183.

Leifert, C., A. Cassells. 2001. Microbial hazards in plant tissue and cell cultures in vitro. Cell Dev. Biol. Plant 37(2):133-138.

Martínez. M., J. Pacheco. 2006. Protocolo para la micropropagación de Furcraea microphylla Baker. Agronomía Colombiana 24(2): 207-213.

Michigan State University. 1989. MSTAT-C. A software program for the design, management, and analysis of agronomic research experiments. Russell, D.F. (Director MSTAT). Michigan State University, Department of Crop and Soil Sciences and Department of Agricultural Economic, East Lansing, Michigan, USA.

Murashige, T., F. Skoog. 1962. A revised médium for rapid growth and biossays of tobacco cultures. Physiological Plantarum 15: 473-497.

Mroginski, E., H. Rey, A. Mroginski. 2003. In vitro plantlet regeneration from Australian Red Cedar (Toona ciliata, Meliaceae). New Forests 25: 177184.

Neill, D., N. Revelo. 1998. Silvicultural trials of Mahogany (Swietenia macrophylla) interplanted with two Inga species in Amazonian Ecuador. In the genus Inga: utilization. Terence D. Pennington y Erick C. Fernades. Kew, In. The Royal Botanical Gardens. p. 141-150.

Pérez, F., M. Aguilar, T. Roca. 2012. Assays for the in vitro establishment of Swietenia macrophylla and Cedrela odorata. Rev. Colomb. Biotecnol. 14(1): 20-30

Pérez, J., F. Mesén, M. Aguilar, L. Hilje. 2006. Desarrollo de un método de micropropagación aplicable a genotipos selectos de Cedrela odorata L. Fases de desarrollo y enraizamiento. Recursos Naturales y Ambiente 46-47: 146-151.

Pierik, R. 1990. Cultivo in vitro de plantas superiores Ediciones mundi-prensa. Madrid España 326 pp.

Prado, L., C. Samaniego, J. Ugarte-Guerra. 2012. Estudio de las cadenas de abastecimiento de germoplasma forestal en Ecuador. ICRAF working paper No 115. World Agroforestry Centre (ICRAF), Lima, Peru.
Quinto, L., P. Martínez-Hernández, L. PimentelBribiesca, D. Rodríguez-Trejo. 2009. Alternativas para mejorar la germinación de semillas de tres árboles tropicales. Revista. Chapingo 15(1): 23-28.

Rebolledo, V., R. Aparicio, A. Cruz. 2006. Estudio preliminar para la propagación in vitro de dos especies de pinos. Foresta Veracruzana 8(2):19-22.

RISE (Reforestation Species). 1995. Mahogany (Swietenia macrophylla King) and Narra (Pterocarpus spp.). Ecosystem Research and Development Bureau College. Languna Philippines, 7(1).

Sánchez, M., D. Ríos, M. Pedraza, G. Pereira, H. Castellanos, R. Escobar. 2004. Propagación in vitro de Nothofagus procera ((Poepp. et Endl.) Oerst) a partir de embriones aislados, Revista Forestal, Bosque 25(1): 123-128.

Silva, L., P. de Tarso, S. de Souza, C. de Queiroz, H. Brandão. 2010. Efeito de diferentes reguladores de crescimento na regeneração in vitro de pau-rosa (Aniba rosaeodora Ducke). Acta Amaz. 40(2): 275-279.

Tacoronte, B. 1998. Cultivo in vitro. Una alternativa de propagación vegetativa en caoba, Swietenia macrophylla King. Revista Forestal Venezolana 42(1): 235-238

Uribe, M., C. Delaveau, M. Garcés, R. Escobar. 2008. Efecto de asepsia y fitohormonas en el establecimiento in vitro de Berberidopsis corallina, a partir de segmentos nodales. Bosque 29(1): 5864.

Valverde, L., M. Dufour, V. Villalobos. 1998. In vitro organogénesis in Albizia guachapele, Cedrella odorata and Swietenia macrophylla (Fabácea, meliácea). Rev. Trop., 46(2): 225-228.

Vázquez, E., S. Torres. 1995. Fisiología Vegetal. Editorial Pueblo y Educación. Segunda edición. Ciudad de la Habana.

Winograd, M. 1995. Indicadores ambientales para Latinoamérica y el Caribe: Hacia la sostenibilidad en el uso de tierras. San José, C R. GASE, Proyecto IICA/GTZ, OEA, WRI, p. 85. 